\title{
Ground motion and rupture process of the 2004 Mid Niigata Prefecture earthquake obtained from strong motion data of K-NET and KiK-net
}

\author{
R. Honda ${ }^{1}$, S. Aoi ${ }^{1}$, N. Morikawa ${ }^{1}$, H. Sekiguchi ${ }^{2}$, T. Kunugi ${ }^{1}$, and H. Fujiwara ${ }^{1}$ \\ ${ }^{1}$ National Research Institute for Earth Science and Disaster Prevention, Japan \\ ${ }^{2}$ National Institute of Advanced Industrial Science and Technology, Japan
}

(Received March 2, 2005; Revised May 2, 2005; Accepted May 11, 2005)

\begin{abstract}
The 2004 Mid Niigata Prefecture earthquake $\left(37.289^{\circ} \mathrm{N}, 138.870^{\circ} \mathrm{E}, 13.1 \mathrm{~km}, \mathrm{M}_{\mathrm{JMA}} 6.8\right.$; JMA), also known as the 2004 Niigata Prefecture Chuetsu earthquake, was a thrust type earthquake that occurred on October 23, 2004 at 17:56 (JST). Strong ground motions of PGA $800-1700 \mathrm{~cm} / \mathrm{s}^{2}$ and PGV $60-130 \mathrm{~cm} / \mathrm{s}$ were observed at stations located immediately above the source region. We deduced the rupture process of this earthquake with a multi-time-window linear waveform inversion procedure. We used near-fault strong ground motion data observed at nine K-NET and KiK-net stations within $50 \mathrm{~km}$ from the epicenter. In order to obtain appropriate Green's functions for the waveform inversion, we constructed two velocity structure models for stations on the hanging wall and one structure model for stations on the footwall. The estimated total slip distribution contains three asperities: (a) around the hypocenter, (b) in the upper-middle section of the fault plane, and (c) southwest of the hypocenter. The maximum slip is $3.8 \mathrm{~m}$ at the hypocenter and the total seismic moment is $1.2 \times 10^{19} \mathrm{Nm}$, which corresponds to $\mathrm{M} w=6.7$. The moment rate functions in asperities (a) and (c) have a short rise time, while those in asperity (b) have a longer rise time.
\end{abstract}

Key words: 2004 Mid Niigata Prefecture earthquake, rupture process, strong motion, K-NET, KiK-net.

\section{Introduction}

On October 23, 2004 at 17:56 (JST), the 2004 Mid Niigata Prefecture earthquake $\left(\mathrm{M}_{\mathrm{JMA}}\right.$ 6.8; Japan Meteorological Agency) struck mid-Niigata Prefecture, central Japan. The mechanism of the earthquake is estimated by Hi-net (High-sensitivity seismograph network; Obara, 2002) and F-net (Full range seismograph network of Japan; Fukuyama et al., 1996) to have been a reverse fault dipping to the northwest, as shown in Fig. 1.

Strong motions of several dozen to more than one hundred $\mathrm{cm} / \mathrm{s}$ were observed mainly at stations on the northwest side of the causative fault, where deep basins exist (e.g., Kobayashi et al., 1991; Yanagisawa et al., 1986). These strong ground motions caused serious devastation such as house collapses and landslides.

In this paper, we review the characteristics of the strong ground motions observed by K-NET (Kinoshita, 1998) and KiK-net (Aoi et al., 2000) during the 2004 Mid Niigata Prefecture earthquake and estimate the rupture process by waveform inversion analysis. Three different velocity structure models are constructed to obtain appropriate Green's functions for the waveform inversion.

\section{Strong Motion Observation}

A total of 587 stations of the K-NET and KiK-net strong motion seismograph networks developed by the National Research Institute for Earth Science and Disaster Preven-

Copy right(c) The Society of Geomagnetism and Earth, Planetary and Space Sciences (SGEPSS); The Seismological Society of Japan; The Volcanological Society of Japan; The Geodetic Society of Japan; The Japanese Society for Planetary Sciences; TERRAPUB tion (NIED) observed ground motion due to this earthquake. Most of the records were collected within 12 hours by dial-up operation from the data management center of NIED.

Relatively large peak ground acceleration (PGA) and peak ground velocity (PGV) were observed in the Tonegawa Lowland, Kinugawa Lowland, and the Kanto region, where deep basins exist (left panels in Fig. 2). Focusing on the near-source region, ground motions larger than $800 \mathrm{~cm} / \mathrm{s}^{2}$ and $60 \mathrm{~cm} / \mathrm{s}$ were observed at several stations above the source region (center panels in Fig. 2). The maximum PGA, $1700 \mathrm{~cm} / \mathrm{s}^{2}$, was recorded at station NIG021 (K-NET). At NIG019, both the PGA and PGV were large with amplitudes of $1300 \mathrm{~cm} / \mathrm{s}^{2}$ and $130 \mathrm{~cm} / \mathrm{s}$, respectively.

The right panels in Fig. 2 show a comparison between the observed peak ground motions and empirical attenuation relationships by $\mathrm{Si}$ and Midorikawa (1999). In the right-hand figure we have corrected the observed PGVs on the surface to the values for "stiff soil" where the $S$ wave velocity is $600 \mathrm{~m} / \mathrm{s}$, following the method of $\mathrm{Si}$ and Midorikawa (1999). The ground motions at NIG019 and NIG021 mentioned above are conspicuously larger than the empirically predicted values. These discrepancies are considered to arise from amplification by the underground structure and/or an inhomogeneous rupture process. The JMA Ojiya Station, located about $800 \mathrm{~m}$ from NIG019, also recorded a PGA larger than $900 \mathrm{~cm} / \mathrm{s}^{2}$. The velocity seismograms observed at NIG019 and the JMA Ojiya Station are similar to each other in the frequency range lower than $0.67 \mathrm{~Hz}$ (1.5 seconds), although the PGA at NIG019 is about $50 \%$ larger than that at the Ojiya Station. Aoi et al. 


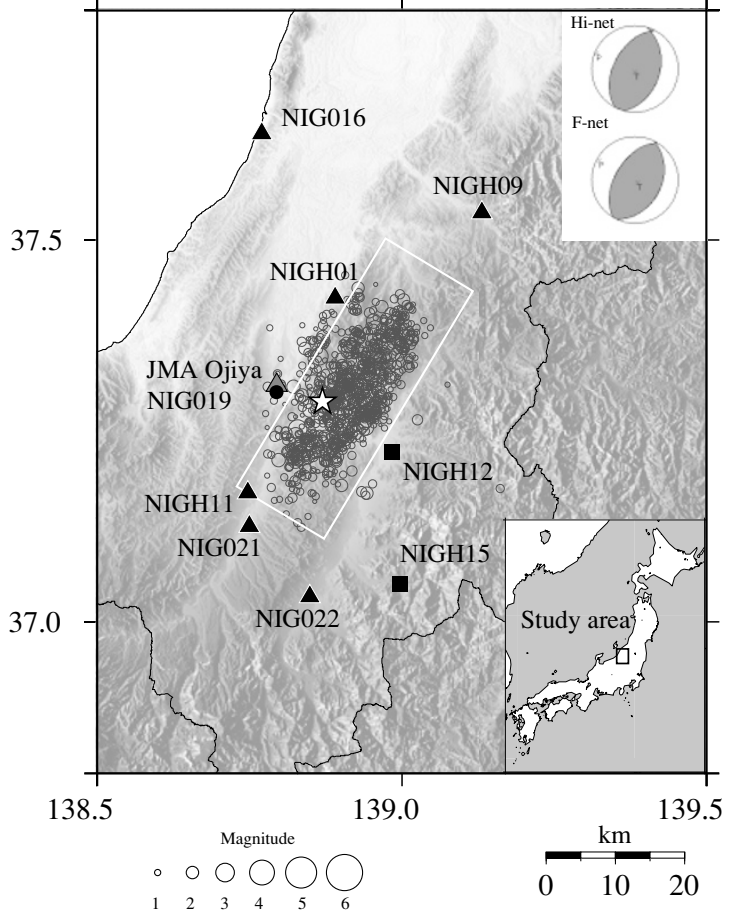

Fig. 1. Distribution of the observation stations. The gray triangle shows JMA Ojiya. The other symbols indicate the velocity structure models used for each station. Stations using the hanging wall model and the footwall model are indicated by triangles and rectangles, respectively. At NIG019, marked by a circle, a velocity structure model only for NIG019 is introduced. The white rectangle delineates the margin of the assumed fault plane. The gray circles are aftershock epicenters within 24 hours after the main shock obtained by the JMA unified catalog. The sizes of the circles vary with the magnitude.

(2005) reported that significant differences in the spectrum amplitude appeared mainly in the frequency range higher than $1 \mathrm{~Hz}$.

The observed velocity seismograms show different features according to the location of the stations. Lowfrequency dominant waveforms are observed at the stations located on the southeast side of the causative fault. In contrast, a large, brief pulse commonly appears at the stations on the northwest side. Such pulses which recorded at south stations of the northwest side (e.g., NIG022) arrived a few seconds later than the expected direct $S$-wave arrival from the hypocenter. On the other hand, at the north stations (e.g., NIG019), such pulses arrived on time expected as arrival time from the hypocenter. These delays do not appear in the aftershock records, and the delays are longer than expected from the thickness and $S$-wave velocity of the sediments beneath the stations. This implies that the delays are not caused by the subsurface structure.

\section{Rupture Process of the 2004 Mid Niigata Pre- fecture Earthquake}

\subsection{Fault plane model}

We constructed a fault model for our waveform inversion analysis in order to clarify the rupture process. The fault size was assumed to be $42 \times 24 \mathrm{~km}$ to cover aftershock distribution within 24 hours after the main shock (Fig. 1). We set subfault size so that the expected predominant frequency due to the subfault size became slightly higher than the frequency range of the present study. We adopted $\mathrm{N} 211^{\circ} \mathrm{E}$ and $52^{\circ}$ as the strike and dip angles, respectively, of the moment tensor solution of F-net (Fig. 1). Referring to the hypocenter of $37.289^{\circ} \mathrm{N}, 138.870^{\circ} \mathrm{E}, 13.1 \mathrm{~km}$ determined by the JMA unified catalog, we assumed a rupture starting point in our rupture process model of $13.4 \mathrm{~km}$ below the epicenter.

\subsection{Data and method}

Strong motion data from nine stations of K-NET and KiK-net whose distances from the epicenter were less than $50 \mathrm{~km}$ were used for the analysis. We preferred KiK-net borehole stations which are expected to be less affected by site effects due to surface layers. Additionally, several K-NET stations were used to improve station coverage. We avoided using records which include dominant surface waves. The locations of the stations are shown in Fig. 1. The observed acceleration records were integrated into the velocity and were band-pass filtered between 0.1 and 0.67 $\mathrm{Hz}$ after correction of the horizontal component directions of the record (Shiomi et al., 2003). We inverted $10 \mathrm{sec}$ onds of the $S$-wave portion from 1 second before $S$-wave arrivals. Theoretical Green's functions were calculated by the discrete wavenumber method (Bouchon, 1981) and the reflection/transmission coefficient matrix method (Kennett, 1983) with stratified media as shown in Fig. 3. We introduced three types of structure models corresponding to the stations on the hanging wall, on the footwall, and NIG019. The details are described in the next section.

In order to represent rupture propagation in each subfault, the moving dislocation effect was considered following Sekiguchi et al. (2002). We used the multi-timewindow linear waveform inversion procedure (Hartzell and Heaton, 1983), in which the moment-release distribution is discretized both in space and time. For discretization in space, we divided the fault plane into 252 subfaults with a size of $2 \mathrm{~km} \times 2 \mathrm{~km}$. The subfault size was chosen so that the expected predominant frequency due to the subfault size (periodicity of point sources) became higher the frequency range of the analysis. We applied nine smoothed ramp functions of 0.7 seconds duration at 0.35 -second intervals to represent the slip history on each subfault. The triggering front of the first-time-window (first ramp function) propagates at a constant velocity, and multi-time-window analysis allows variable rupture velocity and slip duration to be determined in inverted rupture models by weighted time windows. In order to suppress instability or excessive complexity, a smoothing constraint to reduce differences of slips close in space and time was introduced. Non-negative constraints (Lawson and Hanson, 1974) to limit the rake-angle variation were also adopted. The rake angles were allowed to vary within $45^{\circ}$ centered at $93^{\circ}$, which is the rake angle of the moment tensor solution of F-net. We performed many inversions, varying the first-time-window triggering velocity and the smoothing strength. Appropriate values for the smoothing strength and the propagation velocity of the firsttime-window triggering were selected based on Akaike's Bayesian Information Criterion (ABIC; Akaike, 1980) and the residual of the waveform fitting, respectively. 

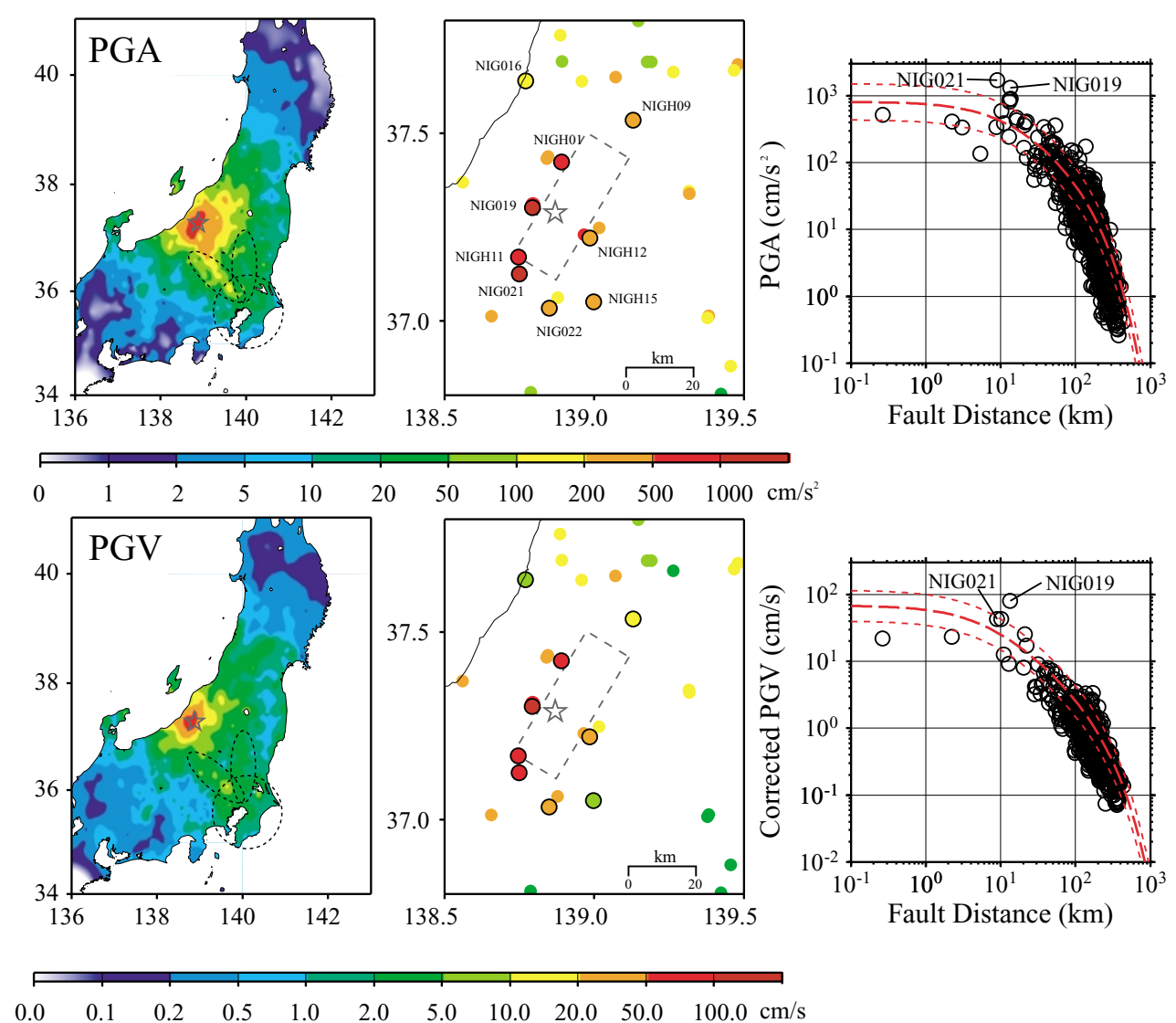

Fig. 2. Top and middle: Distributions of observed peak ground acceleration (PGA; left side) and peak ground velocity (PGV; right side) by K-NET, KiK-net, and JMA stations on the surface. The dotted circle represents the Kanto region. The left and right dotted ellipses show the Tonegawa Lowland and Kinugawa Lowland, respectively. The star indicates the hypocenter, and the dashed rectangle delineates the margin of the assumed fault plane. Stations used for the inversion analysis are ringed by a black line. Bottom: Comparison between observed peak ground motions (circles) and empirical attenuation relationships by Si and Midorikawa (1999) (red dashed lines). PGV which observed at JMA stations are not included in the figure. The red dotted lines represent the standard deviations of the empirical relationships.
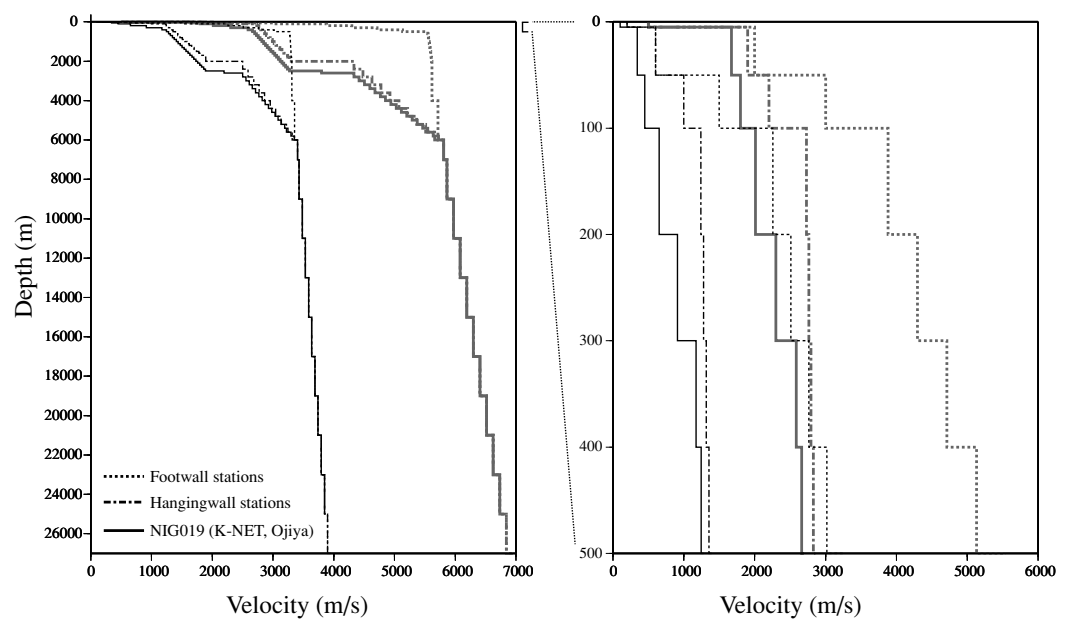

Fig. 3. Velocity structure models used for the analysis. The thick gray lines and thin black lines correspond to the $P$-wave and $S$-wave velocities, respectively. The solid lines indicate the velocity for NIG019. The thin dashed-dotted lines and dotted lines show the structures for the hanging wall and the footwall, respectively. The right figure shows the shallow part of the structures.

\subsection{Velocity structures}

In order to calculate suitable Green's functions, we constructed velocity models replacing the shallow part of the crust and upper mantle model proposed by Ukawa et al. (1984) according to geological information and borehole logging data. The underground structure of the source region is divided into two parts by Shibata-Koide Tectonic Line. The causative fault is estimated to have occurred along this tectonic line. To the southeast of the tectonic line there are outcrops of Pre-Neogene hard rocks, and on 


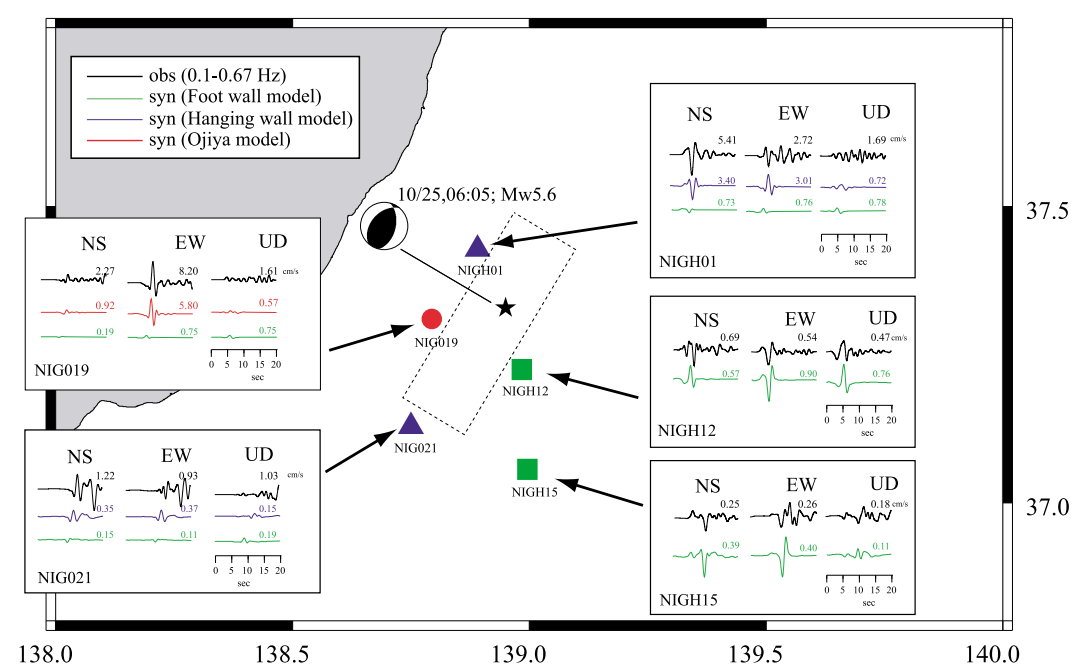

Fig. 4. Comparison between observed and synthetic seismograms for an aftershock that occurred on October 25 . The black lines show the observed seismograms. The red, blue, and green lines show synthetic seismograms calculated with the velocity models for NIG019, hanging wall stations, and foot wall stations, respectively. The dotted rectangle delineates the margin of the assumed fault plane. The other symbols are the same as those in Fig. 1.

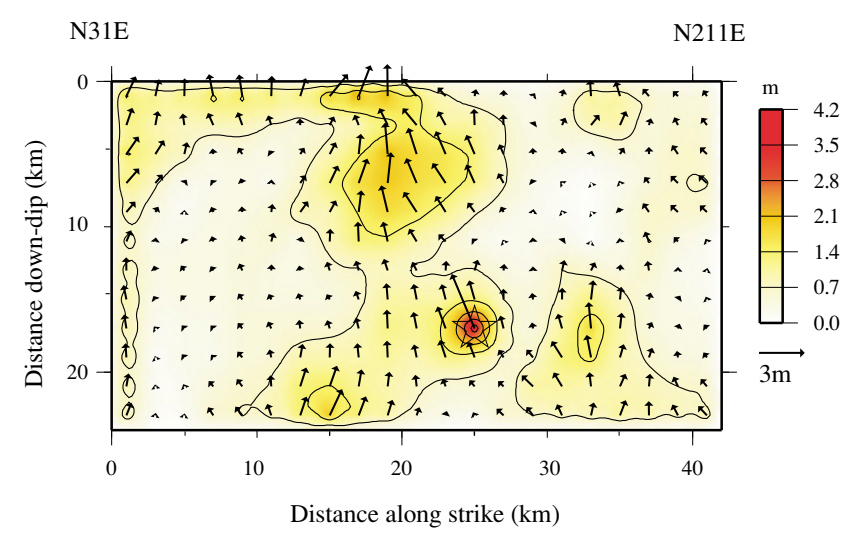

Fig. 5. Distributions of coseismic slip obtained for the 2004 Mid Niigata Prefecture earthquake. The star indicates the hypocenter. The arrows show the amplitude and directions of slip. The largest slip occurred at the hypocenter. The contour interval is $0.7 \mathrm{~m}$. The distance between the center of each subfault is $2 \mathrm{~km}$.

the northwest side there are deep sedimentary basins.

Several geophysical studies (e.g., Kobayashi et al., 1991) have shown that the thickness of the sedimentary layers on the northwest side of the tectonic line, which corresponds to the hanging wall of our fault model, reaches several kilometers. METI (Ministry of Economy, Trade and Industry, 2001) drilled a deep borehole at a sediment site near Ojiya. The borehole reached bedrock beneath the sediment at $6 \mathrm{~km}$ deep. They reported that there was a significant step of $P$-wave velocity at $2-2.5 \mathrm{~km}$ deep. For the hanging wall stations, we constructed a velocity model with a $6 \mathrm{~km}$ sedimentary basin based on the geological information and borehole logging data.

For the stations southeast of the tectonic line, that is, the footwall stations, we introduced sedimentary layers of several hundred meters in depth based on geological information (e.g., Yanagisawa et al., 1986). We then modified the shallowest part of our velocity structure models, based on

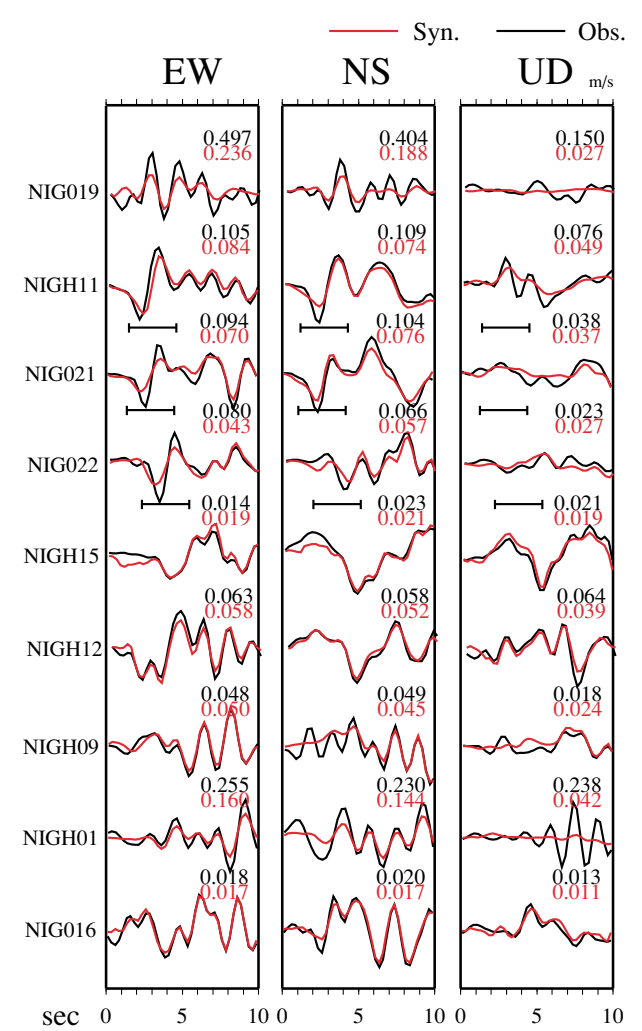

Fig. 6. Comparison between observed and synthetic velocity waveforms. The maximum values of each component are given to the right of each trace in $\mathrm{m} / \mathrm{s}$. Each trace is normalized by the maximum amplitude recorded at each station.

borehole logging data of K-net and KiK-net stations for depths ranging from a few dozen to several hundred meters.

We found a large discrepancy between the observations and synthetic seismograms for aftershocks in the case of NIG019 on the hanging wall. Therefore, we constructed another velocity structure model for NIG019 referring to Yamanaka et al. (2005). They modeled the velocity structure 

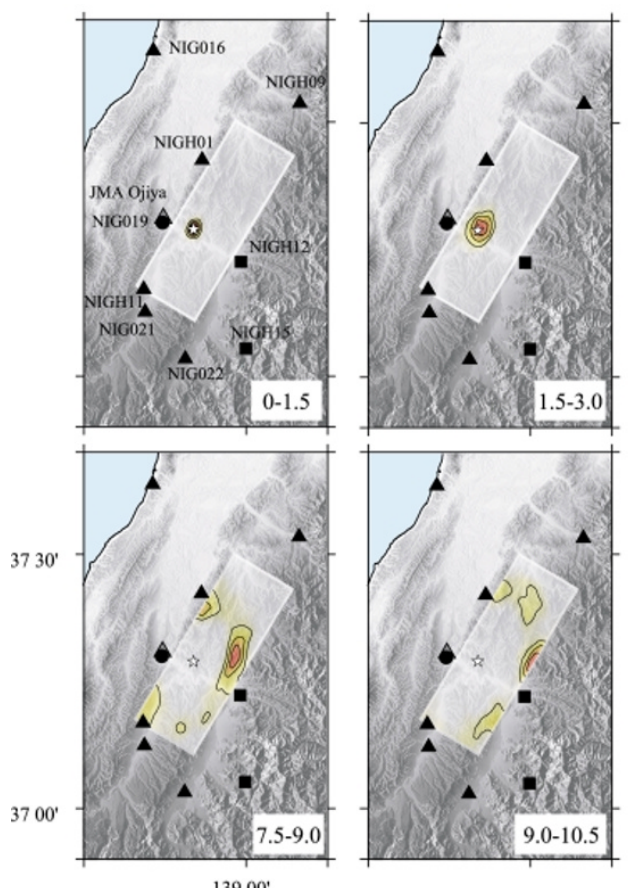
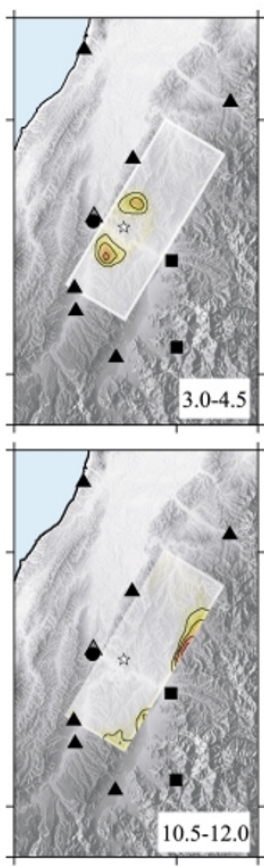
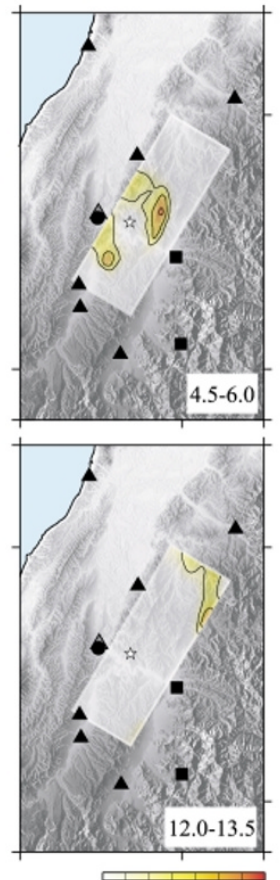

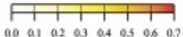

Slip rate $(\mathrm{m} / \mathrm{s})$
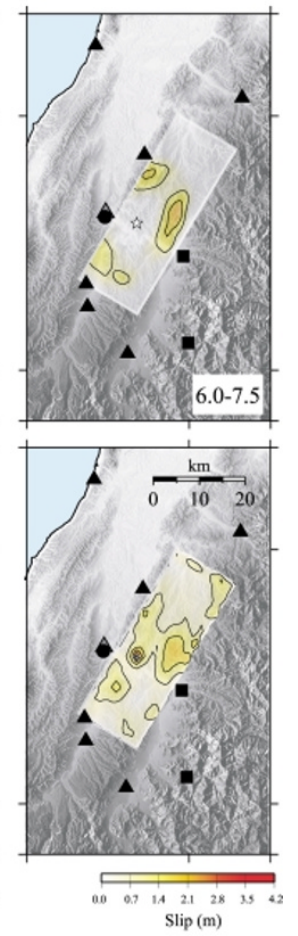

Fig. 7. Snapshots of the rupture progression at time step of 1.5 seconds. The contour interval of the slip velocity is $0.1 \mathrm{~m} / \mathrm{s}$. The star indicates the hypocenter. The numbers at the bottom right of each figure show the time after the start of rupture. The symbols for the observation stations are the same as those in Fig. 1. The figure at bottom right shows the total slip distribution.

beneath NIG019 from array observations of microtremors. The model for NIG019 had a sedimentary basin with slower $P$ - and $S$-wave velocities than those for the other hanging wall stations.

Using these as initial models, we modified their layer depths through trial and error by forward modeling to fit the synthetic seismograms to the observed seismograms for several aftershocks. The final models that we used for calculation of the Green's functions are shown in Fig. 3. The classifications of the stations by velocity model are shown in Fig. 1. Figure 4 compares the observed and synthetic seismograms at three stations for an aftershock that occurred on October 25, 2004. The observed waveforms are explained well by our velocity structure models in the frequency range of $0.1-0.67 \mathrm{~Hz}$.

\subsection{Inversion results}

Figure 5 shows the total slip distribution obtained by the waveform inversion analysis. The result shows an almost pure dip slip fault mechanism. Figure 6 compares the observed and synthetic seismograms for the estimated rupture process. We can see two major asperities: (a) around the hypocenter, and (b) in the upper-middle section of the fault plane. The largest slip of $3.8 \mathrm{~m}$ occurs at asperity (a). Asperity (a) contributes to the waveforms observed at the northern stations (e.g., NIG019, NIGH01). In particular, the main pulses observed at NIG019 are generated by this largest slip. The waveforms observed at the footwall stations, NIGH12 and NIGH15, are mainly generated from asperity (b). An additional small asperity (c) southwest of the hypocenter plays an important role in explaining the characteristic waveforms that are widely observed to the southwest of the source region. The solid lines under the seismograms

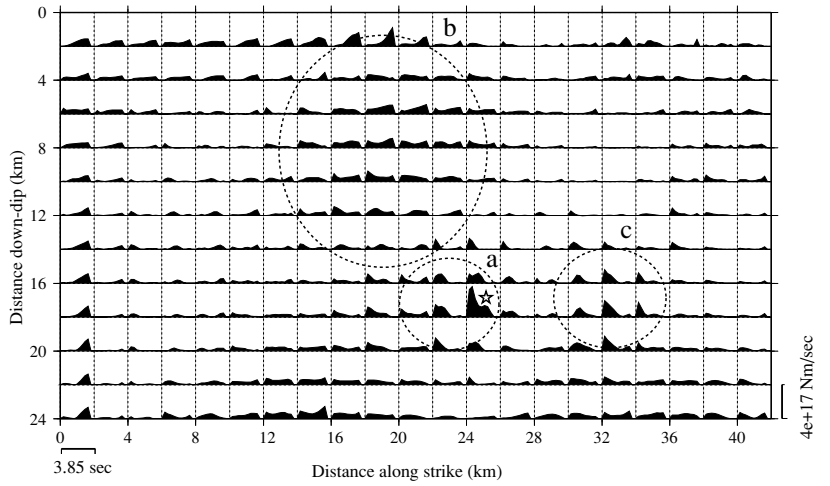

Fig. 8. Moment rate functions for each subfault. The star indicates the hypocenter and dotted circles are asperities obtained by the inversion analysis.

observed at NIG012, NIG022, and NIGH11 indicate pulses from this small asperity. The overall waveform matching is good at all the stations.

The time progression of the rupture is shown in Figs. 7 and 8. Slip at the hypocenter is dominant for 3 seconds after the start of the rupture. The small asperity to the southwest of the hypocenter ruptures at 3.0-6.0 seconds after the start of the rupture. Although rupture propagates to north simultaneously, its contribution to waveforms is not large. The major rupture propagates toward the east with a velocity of $2200 \mathrm{~m} / \mathrm{s}$. This is about $67 \%$ of the $S$-wave velocity at the hypocenter. The total seismic moment is $1.2 \times 10^{19} \mathrm{Nm}$, which corresponds to $\mathrm{M} w 6.7$. 


\section{Discussion and Conclusions}

We performed multi-time-window linear waveform inversion for the rupture process of the 2004 Mid Niigata Prefecture earthquake using three velocity structure models. We constructed two velocity structure models for stations on the hanging wall side and one for those on the footwall side, referring to geological information, borehole data, and microtremor observation results (Yamanaka et al., 2005). We then improved these models by forward modeling for several aftershocks. Synthetic waveforms calculated by the improved velocity structure models agree well with the observed waveforms. Using these models, synthetic and observed seismograms for the main shock fit well at most stations, including the absolute amplitude and alignment of conspicuous phases. However, a detailed investigation reveals that some discrepancies still remain. The amplitudes of the main shock waveforms at NIG019 are underestimated and there are notable misfits for the U-D component at NIGH01 in Fig. 6. Although we have examined our velocity models carefully at several hanging wall stations, the amplitudes of the synthetic seismograms are still underestimated (Fig. 3). Moreover, the dominant surface waves cannot be represented. The results of the geophysical exploration now under way may provide us with valuable information for modifying the underground structure models.

The moment rate functions differ from each other according to the depth of the asperity (Fig. 8). The moment rate functions of the two deep asperities, (a) and (c), have a short rise time and a sharp peak. Seismic waves radiated from these asperities largely contribute to the generation of the large, brief pulses at stations on the hanging wall. In contrast, the source time functions of the shallow asperity (b) have a longer rise time, and cause ground motion with a dominant low frequency. This rise time variation suggests that the stress drop at the deeper asperities is larger than that at the shallower asperity.

As mentioned in Section 2, arrival time of main phases at southern stations on the hanging wall are significantly later than expected arrival time of direct $S$-wave from the hypocenter,. This is because contribution of asperity (c) is most dominant in waveform of the south stations and asperity (a) hardly contributes to waveform of those stations. Kamae et al. (2005) also obtained a small asperity at the southwest of the epicenter by the empirical Green's function method. They concluded that a small asperity was essential to reproduce high-frequency ground motions with large peak acceleration recorded at NIG021 and NIG022. These results suggest that time delay of remarkable pulses observed at the southern stations is owing to locations of asperity which contribute to the waveforms.

Our inversion results show that the rupture propagated from the hypocenter mainly toward the up-dip direction. This corresponds well with the fact that the centroid depth of the moment tensor solution, $5 \mathrm{~km}$ as determined by Fnet, is shallower than the depth of the hypocenter, $13 \mathrm{~km}$, determined by Hi-net data.

Acknowledgments. We would like to express our deep appreciation to Dr. H. Yamanaka for providing the velocity model. We would also like to thank Dr. H. Hayashi for his valuable advice related to geological studies. We are deeply grateful to reviewers, Dr. P. M. Mai and Dr. Y. Kakehi. Suggestions and comments from them were valuable in improving this manuscript. This work is being conducted under the auspices of the "National Strong Motion Mapping Project" of the National Research Institute for Earth Science and Disaster Prevention, Japan. GMT (Wessel and Smith, 1995) was used to prepare the figures.

\section{References}

Akaike, H., Likelihood and the Bayes procedure, in Bayesian Statics, University Press, Valencia, Spain, 1980

Aoi, S., K. Obara, S. Hori, K. Kasahara, and Y. Okada, New StrongMotion Observation Network: KiK-net, EOS Trans. Am. Geophys. Union, p. 329, 2000.

Aoi, S., N. Morikawa, R. Honda, H. Sekiguchi, T. Kunugi, and H. Fujiwara, Large ground-motion observed during 2004 Niigata-ken Chuetsu Earthquake, Report on the Damage Investigation of the $2004 \mathrm{Mid} \mathrm{Ni}$ igata Prefecture Earthquake, 10-17. Japanese Geotechnical Society, 2005 (in Japanese).

Bouchon, M., A simple method to calculate Green's function for elastic layered media, Bull. Seis. Soc. Am., 71, 959-971, 1981.

Fukuyama, E., M. Ishida, S. Hori, S. Sekiguchi, and S. Watada, Broadband seismic observation conducted under the FREESIA Project, Rep. Nat'l. Res. Inst. Earth Sci. Disas. Prev., 57, 23-31, 1996.

Hartzell, S. H. and T. Heaton, Inversion of strong ground motion and teleseismic waveform data for the fault rupture history of the 1979 Imperial Valley, California, earthquake, Bull. Seis. Soc. Am., 73, 1553$1583,1983$.

Kamae, K., T. Ikeda, and S. Miwa, Source model composed of asperities for the 2004 Mid Niigata Prefecture, Japan, earthquake $\left(\mathrm{M}_{\mathrm{JMA}}=6.8\right)$ by the forward modeling using the empirical Green's function method, Earth Planets Space, 57, this issue, 533-538, 2005.

Kennett, B. L. N., Seismic Wave Propagation in Stratified Media, Cambridge University Press, Cambridge, 1983.

Kinoshita, S., Kyoshin net (K-NET), Seism. Res. Lett., 69, 309-332, 1998. Kobayashi, I., M. Takeishi, T. Yoshioka, and M. Shimazu, Geology of the Nagaoka district with geological sheet map at 1:50,000. Geological Survey of Japan, 132 pp., 1991 (in Japanese with English abstract).

Lawson, C. and R. Hanson, Solving Least Squares Problems, PrenticeHall, Inc., New Jersey, 1974.

Ministry of Economy, Trade and Industry, Report on Fundamental Exploration for Oil and Gas Resources in Japan, Fundamental Exploration Test Well "OGUNI", p. 44, Japan Oil National Corporation, 2001.

Obara, K., Hi-net: High sensitivity seismograph network, Japan, Lecture Notes in Earth Sciences, 98, 79-87, 2002.

Sekiguchi, H., K. Irikura, and T. Iwata, Source inversion for estimating continuous slip distribution on the fault-Introduction of Green's functions convolved with a correction function to give moving dislocation effects in subfaults, Geophys. J. Int., 150, 377-391, 2002.

Shiomi, K., K. Obara, S. Aoi, and K. Kasahara, Estimation on the azimuth of the Hi-net and KiK-net borehole seismometers, ZISIN, 56(1), 99110, 2003 (in Japanese with English abstract and figure captions).

$\mathrm{Si}, \mathrm{H}$. and S. Midorikawa, New attenuation relationships for peak ground acceleration and velocity considering effect of fault type and site condition, J. Struct. Constr. Eng., 523, 63-70, 1999 (in Japanese with English abstract and figure captions).

Ukawa, M., M. Ishida, S. Matsumura, and K. Kasahara, Hypocenter determination method of the Kanto-Tokai observational network for microearthquakes, Rep. Nat'l. Res. Inst. Earth Sci. Disas. Prev., 53, 1-88, 1984

Wessel, P. and W. Smith, New version of the generic mapping tools, EOS Trans. Am. Geophys. Union, 76, 1995.

Yamanaka, H., K. Motoki, S. Fukumoto, H. Takahashi, N. Yamada, and K. Asano, Estimation of local site effects in Ojiya city using aftershock records of the 2004 Mid Niigata Prefecture earthquake and microtremors, Earth Planets Space, 57, this issue, 539-544, 2005.

Yanagisawa, Y., I. Kobayashi, K. Takeuchi, M. Takeishi, K. Kayahara, and T. Kato, Geology of the Odiya district with geological sheet map at 1:50,000, Geological Survey of Japan, 132 pp., 1986 (in Japanese with English abstract).

R. Honda (e-mail: ryou@onken.odawara.kanagawa.jp), S. Aoi, N. Morikawa, H. Sekiguchi, T. Kunugi, and H. Fujiwara 